\title{
Therapeutic efficacy of naringin on cyclosporine (A) induced nephrotoxicity in rats: Involvement of hemeoxygenase-1
}

\author{
Yamini Chandramohan, Chetenchery Somasundaram Parameswari \\ Post-Graduate Department of Biochemistry, Bharathi Women's College (Autonomous), Prakasam Salai, \\ North Chennai 600 108, Tamil Nadu, India
}

Correspondence: Chetenchery Somasundaram Parameswari, e-mail: csparameswari@gmail.com

\begin{abstract}
:
Background: Clinically, chronic nephrotoxicity may lead to renal functional impairment and progress to end stage renal failure. The renoprotective effect of a flavonoid naringin (NG) against cyclosporine A(CsA)-induced nephrotoxicity was investigated in this study. Methods: Nephrotoxicity was induced in male albino Wistar rats by injecting $25 \mathrm{mg} / \mathrm{kg}$ body weight of CsA for a period of 21 days. CsA-induced rats were also cotreated with $40 \mathrm{mg}$ of NG/kg body weight, orally.

Results: After the experimental period, the levels of lipid peroxides (TBARS) and hydroxyl radical $\left(\mathrm{OH}^{\circ}\right)$ were found to be elevated, whereas the levels of SOD, catalase, glutathione, vitamin C, E and A were decreased in CsA-induced rats. NG co-treatment significantly decreased the levels of lipid peroxides and hydroxyl radicals and restored the levels of enzymic and non-enzymic antioxidants in renal tissues. Histological analysis revealed that CsA administration caused severe and widespread necrosis with dilatation of proximal tubules, vacuolization, tubular cell desquamation and intraluminal cast formation with massive infiltration of inflammatory cells. CsA-induced histopathological renal changes were minimal in animals which received NG treatment. The western blot and confocal microscopic expression of heme oxygenase-1 was restored by NG. In CsA-induced animals the expression was reduced compared to NG treated animals.

Conclusions: The present study reveals that NG can act as effective renoprotective drug against CsA-induced toxicity.
\end{abstract}

Key words:

cyclosporine, naringin, lipid peroxidation, heme oxygenase, nephrotoxicity

\section{Introduction}

The introduction of cyclosporine (CsA) has stimulated a new era in transplantation medicine worldwide, resulting in substantial improvement of the overall success rates after solid organ transplantation. However, graft failure in the long-term remained basically unchanged due to nephrotoxicity [39]. Clinically, chronic nephrotoxicity may lead to renal functional impairment and progress to end stage renal fail- ure. The cause for the nephrotoxicity of CsA has not been fully elucidated. CsA nephrotoxicity is characterized by intense renal vasoconstriction that often progresses to chronic injury with irreversible structural and functional renal damage [7]. During the last decade, considerable attention has been focused on the involvement of reactive oxygen species (ROS) in various organs including the kidney. ROS have been proposed as mediators of different kidney diseases especially in toxic, ischemic or immunological condi- 
tions [34]. The implications of ROS in CsA nephrotoxicity was strengthened by the fact that many antioxidants and free radical scavengers provide marked functional and histopathological protection against CsA nephrotoxicity [60].

The heme oxygenase (HO) enzyme system catalyzes the rate-limiting step in the degradation of heme. Two major HO isoforms have been identified, HO-1 and HO-2, which are the products of different genes. HO-1 (the inducible form) is highly sensitive to numerous stimuli that cause oxidative stress: heme, growth factors, nitric oxide, modified lipids, changes in oxygen tension, cytokines, and therapeutic agents. These stimuli do not activate HO-2, the constitutive form, which is regulated only by glucocorticoids. HO-1 induction has salutary effects in diseases and its protective effects are exhibited by its anti-inflammatory, antiapoptotic, antioxidant, and anti-proliferative properties [32].

The positive role of dietary polyphenol, such as citrus flavanoids, in human health is the object of growing scientific interest. Flavanoids, known as nature's tender drugs, possess various biological and pharmacological activities including antioxidant, antiinflammatory, anticancer, antimicrobial and antiviral [47]. They are a large class of natural polyphenolic compounds, occurring in fruits and vegetables regularly consumed by humans. Naringin (NG), one of the bioflavanoids in grapefruit and citrus fruits, has been reported to exhibit anti-oxidative effects $[16,35]$, and inhibit lipid peroxidation in biological membranes [26]. NG has been demonstrated to have antiviral actions [20], reduce the level of cytochrome P450 1A2 protein [57], and aid in the regulation of lipid and ethanol metabolism [53]. Accordingly, NG has extensive pharmacological activity and may reduce the CsA-induced nephrotoxicity.

In the present study, we investigated the therapeutic effect of NG on renal lipid peroxides, enzymatic, non-enzymatic antioxidants, histological changes in CsA-induced nephrotoxicity and the expression of HO-1 during the experimental period.

\section{Materials and Methods}

\section{Animals}

Male albino rats of Wistar strain $(180 \pm 20 \mathrm{~g})$ were obtained from the Laboratory Animal Maintenance
Unit, Saveetha University, Vellapanchavadi, Chennai, India. The animals were acclimatized to the laboratory conditions for a period of 2 weeks. They were maintained at an ambient temperature of $25 \pm 2^{\circ} \mathrm{C}$ and $12 / 12 \mathrm{~h}$ of light-dark cycle and were given a standard rat feed (Hindustan Lever Ltd., Bangalore) and water ad libitum. The experiments were conducted according to the ethical norms approved by Ministry of Social Justices and Empowerment, Government of India and Institutional Animal Ethics Committee Guidelines.

\section{Experimental design}

The rats were divided into four groups ( $\mathrm{n}=6$ in each group) of the same age. Group 1 served as control animals and received olive oil (vehicle). Group 2 - Rats were administered with CsA (Sandoz Ltd., Switzerland) (25 mg/kg body weight) dissolved in olive oil orally for a period of 21 days. Group 3 - Rats were treated with a single dose with $40 \mathrm{mg} / \mathrm{kg}$ body weight of NG (Sigma Aldrich Co., St. Louis, USA) (based on the effective dosage fixation studies) orally until the end of the experiment, after CsA administration as mentioned in group 2. Group 4 - Rats received the same dose of NG (40 mg/kg body weight) alone as mentioned in group 3 for a period of 21 days.

After the experimental period, the animals were sacrificed and blood was collected and the kidney tissue was washed in physiological saline. For histopathological studies, a piece of $1 \mathrm{~cm}^{3}$ of kidney tissue was cut and placed immediately in phosphate buffered formal saline ( $\mathrm{pH}$ 7.4). The plasma was collected from the blood samples used for the biochemical investigations.

\section{Biochemical studies}

The levels of lipid peroxides were estimated in plasma and kidney tissue by the method of Ohkawa et al. [36]. Hydroxyl radical production was measured in tissue homogenate by the method of Cederbaum and Cohen [9]. Superoxide dismutase was assayed following the method of Misra and Fridovich [28]. Catalase was assayed according to the method of Sinha et al. [55]. Glutathione reductase was assayed by the method of Staal et al. [56]. The activity of glutathione peroxidase was assayed by the method of Rotruck et al. [48]. The activity of glutathione S transferase was assayed by the method of Habig et al. [15]. 
The protein content was determined by the method of Lowry et al. [25]. Renal vitamin $\mathrm{C}$ was estimated by the method of Omaye et al. [38], vitamin E was estimated by the method of Desai [12] and vitamin A was estimated by the method of Bessy [5].

\section{Histopathological analysis}

A portion of the kidney tissue was fixed in $10 \%$ formaldehyde solution and embedded in paraffin. Sections were cut at $4 \mathrm{~mm}$ in thickness, stained with hematoxylin and eosin and viewed under light microscope for histological changes.

\section{Confocal microscopic analysis of $\mathrm{HO}-1$}

Paraffin embedded tissue sections were rehydrated first in xylene and then in graded ethanol solutions. The slides were then blocked with $3 \%$ BSA in TBS for $2 \mathrm{~h}$, immunostained with respective mouse monoclonal primary antibodies HO-1, (Abcam, USA) diluted at appropriate dilutions with $3 \%$ BSA in TBS and incubated overnight at $4^{\circ} \mathrm{C}$. After washing the slides thrice with TBS, the sections were then incubated with goat anti rabbit-FITC conjugated secondary antibody and goat anti rabbit-PE conjugated secondary antibody, diluted 1 : 40 with $3 \%$ BSA in TBS and incubated for $2 \mathrm{~h}$ at room temperature. Slides were counterstained with DAPI and PI, respectively, and were visualized under a confocal microscope (Leica TCS-SP2 XL).

\section{Western blot analysis}

Western blot analysis of HO-1 was performed following the method in [24].

\section{Statistical analysis}

All the data were analyzed using SPSS/10 Student Software. Hypothesis testing methods included oneway analysis of variance (ANOVA). The values are expressed as the mean $\pm \mathrm{SD}, \mathrm{p}$ value of less than 0.05 and 0.001 were considered to indicate statistical significance.

\section{Results}

The body weight of each animal was recorded and percentage of weight gain was noted along with changes in kidney to body weight ratio and presented in Table 1. A significant weight loss and a significant increase $(p<0.001)$ in kidney/body weight ratio was observed as a result of CsA administration compared to the control group. CsA reduces the amount of food intake, which results in well known decreased body weight. Administration of NG markedly increased mean final body weight and decreased the mean kidney to body weight ratio ( $\mathrm{p}<0.001)$. No significant changes in comparison with control (Group 1) and NG treated groups (Group 4) were observed.

Figure 1 shows the effect of CsA and NG on the levels of LPO and $\mathrm{OH}^{-}$in kidney tissue of control and experimental animals. Tissue LPO and $\mathrm{OH}^{\bullet}$ levels were significantly increased in CsA administered group (Group 2) as compared to the control (Group 1). NG supplementation (Group 3) significantly $(\mathrm{p}<0.05)$ decreased the concentration of LPO and $\mathrm{OH}^{*}$ as compared to the CsA induced rats (Group 2). No significant difference was found between control group (Group 1) and NG alone treated animals (Group 4). The enhancement of antioxidant defense by NG has also played a major role to decrease the toxicity in this model which has been established well in other models.

Tab. 1. Body weight gain and changes in kidney body weight ratio of control and experimental animals

\begin{tabular}{lcccc}
\hline Parameters & Control & CsA & CsA + NG & NG \\
\hline Body weight gain (\%) & 35 & $22^{\mathrm{a}}$ & $28^{\mathrm{b}}$ & $33^{\mathrm{ns}}$ \\
Kidney/body weight ratio $(\mathrm{mg})$ & $12.86 \pm 0.05$ & $16.24 \pm 0.25^{\mathrm{a}}$ & $15.32 \pm 0.04^{\mathrm{b}}$ & $13.11 \pm 0.18^{\mathrm{ns}}$ \\
\hline
\end{tabular}

Values are expressed as the mean \pm SD for six animals in each group. ${ }^{a}$ CsA vs. control, ${ }^{b}$ CsA vs. CsA $+N G, p<0.001 ; n s-n o n-s i g n i f i c a n t$ (NG vs. control) 


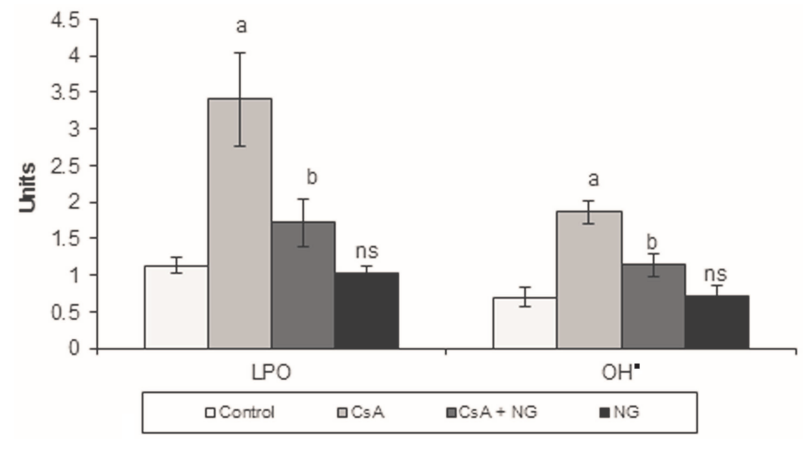

Fig. 1. Effect of naringin (NG) and cyclosporine (CsA) on the levels of lipid peroxidation and hydroxyl radical formation in the kidney of control and experimental group of animals. Values are expressed as the mean \pm SD for six animals in each group. Units: LPO - $\mu$ moles of MDA released/mg of protein, $\mathrm{OH}^{*}-\mathrm{ng} / \mathrm{mg}$ of protein. One way ANOVA followed by post-hoc test LSD. ${ }^{a}$ CsA vs. control, ${ }^{b}$ CsA vs. CsA + NG, p < 0.05; ns - non-significant (NG vs. control)

Table 2 represents the levels of enzymic antioxidants such as SOD, CAT, GPx, GR and GST in the renal tissue homogenate of rats in control and experimental groups. The activities of enzymic antioxidants were significantly $(\mathrm{p}<0.05)$ reduced in CsA induced rats (Group 2) as compared to the control animals
(Group 1). NG administration (Group 3) significantly increased the enzymic antioxidant activity as compared with CsA induced rats (Group 2). No significant changes were observed in NG alone treated group of rats (Group 3) when compared to control.

Table 3 represents the levels of non-enzymic antioxidants such as GSH, vitamin C, vitamin E and vitamin $\mathrm{A}$ in the kidney of control and experimental groups. The levels of non-enzymic antioxidants were significantly $(\mathrm{p}<0.05)$ reduced in CsA-induced rats (Group 2) as compared to the control rats (Group 1), which may be due to increased utilization of these antioxidants to counter lipid peroxidation. NG administration (Group 3) significantly $(p<0.05)$ increased the non-enzymic antioxidant levels as compared with CsA induced rats (Group 2), which in turn may be due to scavenging free radicals and alleviating oxidative stress, thus restoring the levels of vitamin's to near normal. No significant changes were found between control (Group 1) and NG alone treated group of rats (Group 3).

Figure 2 presents the histological changes of renal tissue in control and CsA-induced experimental animals. Histological analysis revealed that CsA admini-

Tab. 2. Effect of CsA and NG on the levels of kidney enzymic antioxidants

\begin{tabular}{ccccc}
\hline Parameters & Control & CsA & CsA + NG & NG \\
\hline SOD & $7.08 \pm 0.45$ & $4.13 \pm 0.56^{\star}$ & $7.01 \pm 0.67^{\star *}$ & $7.29 \pm 0.53^{\mathrm{ns}}$ \\
CAT & $43.20 \pm 2.07$ & $25.15 \pm 2.87^{\star}$ & $39.26 \pm 4.41^{\star *}$ & $42.17 \pm 2.75^{\mathrm{ns}}$ \\
GP & $9.67 \pm 0.87$ & $5.03 \pm 0.75^{\star}$ & $7.35 \pm 0.70^{\star *}$ & $9.82 \pm 0.70^{\mathrm{ns}}$ \\
GR & $4.53 \pm 0.20$ & $2.22 \pm 0.45^{\star}$ & $4.39 \pm 0.39^{\star *}$ & $4.61 \pm 0.27^{\mathrm{ns}}$ \\
GST & $16.95 \pm 1.53$ & $9.47 \pm 1.61^{\star}$ & $16.63 \pm 2.03^{* *}$ & $16.26 \pm 1.58^{\mathrm{ns}}$ \\
\hline
\end{tabular}

Units: SOD - 50\% inhibition of epinephrine autoxidation $/ \mathrm{min} / \mathrm{mg}$ protein; CAT - $\mu$ moles of $\mathrm{H}_{2} \mathrm{O}_{2}$ decomposed $/ \mathrm{min} / \mathrm{mg} \mathrm{protein}$; GPx - $\mu$ moles of GSH oxidized/min/mg protein; GST $-\mu$ moles of CDNB conjugated $/ \mathrm{min} / \mathrm{mg}$ protein. Values are expressed as the mean \pm SD; $n=6$. One way ANOVA followed by post-hoc test LSD $(\mathrm{p}<0.05)$. Comparisons: ${ }^{*}$ control vs. CsA; ${ }^{* \star}$ CsA vs. CsA + NG; ${ }^{n s}$ control vs. NG

Tab. 3. Effect of CsA and NG on the levels of kidney non-enzymic antioxidants

\begin{tabular}{|c|c|c|c|c|}
\hline Parameters & Control & CsA & $\mathrm{CsA}+\mathrm{NG}$ & $N G$ \\
\hline $\mathrm{GSH}$ & $31.60 \pm 2.98$ & $15.21 \pm 2.47^{\star}$ & $27.14 \pm 3.10^{* *}$ & $30.26 \pm 2.79^{n s}$ \\
\hline Vitamin C & $0.74 \pm 0.04$ & $0.42 \pm 0.03^{\star}$ & $0.58 \pm 0.04^{\star *}$ & $0.71 \pm 0.03^{n s}$ \\
\hline Vitamin E & $2.53 \pm 0.12$ & $1.77 \pm 0.22^{\star}$ & $2.09 \pm 0.15^{\star \star}$ & $2.48 \pm 0.09^{n s}$ \\
\hline Vitamin A & $0.10 \pm 0.01$ & $0.03 \pm 0.05^{\star}$ & $0.07 \pm 0.01^{* *}$ & $0.09 \pm 0.01^{n s}$ \\
\hline
\end{tabular}




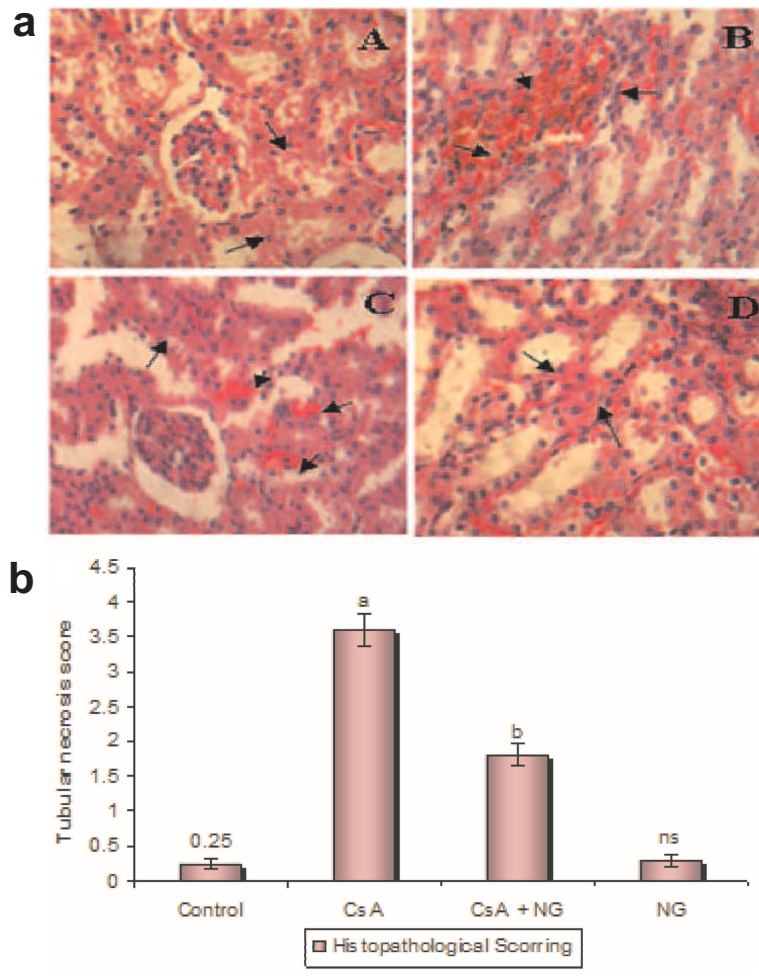

Fig. 2. Effect of naringin on histological analysis of kidney in control and experimental groups of animals. (a) A - Control group; D - NG alone treated group with normal renal histological picture showing intact glomeruli (black arrow). B - CsA-induced group showing damage to the glomeruli with extensive tubular necrosis, tubular dilatation, vacuolization and cast formation with chronic infiltration of inflammatory cells (black arrow). C -- CsA + NG treated group displaying remarkable improvement in the histological appearance of glomeruli with less inflammatory cells. (b) Data are expressed as the mean $\pm \mathrm{SD}, \mathrm{n}=6$ animals. ${ }^{a} \mathrm{CsA}$ vs. control, ${ }^{\mathrm{b}} \mathrm{CsA}$ vs. CsA $+\mathrm{NG}, \mathrm{p}<0.05$; ns - non-significant (NG vs. control)

stration (Fig. 2B) caused severe and widespread necrosis with dilatation of proximal tubules, vacuolization, tubular cell desquamation and intraluminal cast formation with massive infiltration of inflammatory cells. CsA-induced histopathological renal changes were minimal in animals which received NG treatment (Fig. 2C). NG (Fig. 2D) alone treated animals showed normal renal architecture compared to control (Fig. 2A) group of animals. Histopathological scoring was performed by a pathologist unaware of the treatment protocol. Renal tubular damage was evaluated using a semiquantitative scale in which the percentage of tubules showing necrosis was scored as follows: $0=$ normal $; 1=10 \% ; 2=10-25 \% ; 3=25-75 \% ; 4=$ $>75 \%$.

Figure 3 demonstrates confocal microscopic analysis of HO-1, counterstained with PI and the secondary antibody was tagged with Alexa fluor 488. CsA treat-

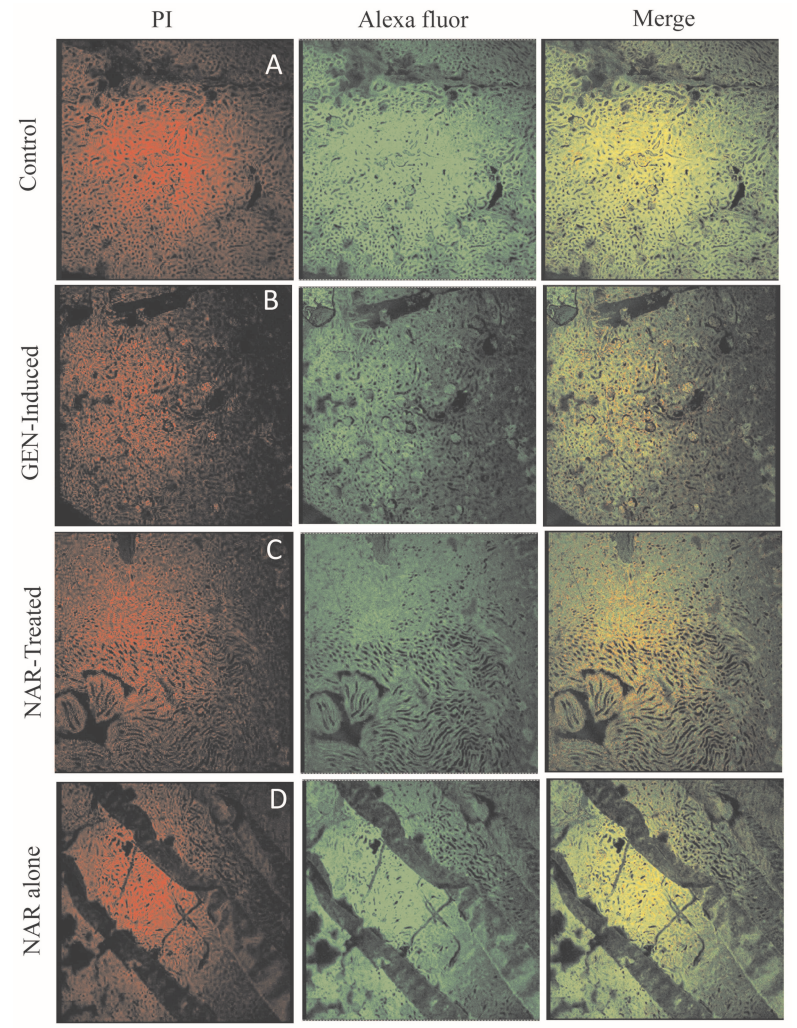

Fig. 3. Effect of NG on confocal microscopic analysis of $\mathrm{HO}-1$ of control and experimental groups of animals. Tissue sections were immunostained with the primary anti-HO-1 antibody and Alexa fluor 488 conjugated secondary antibody (green) viewed under confocal microscopy (magnification 400x). A tissue sections were counterstained with $\mathrm{PI}$ (red) for nuclear localization. (A) Control, (B) CsA-induced showing decreased green fluorescence around the epithelial region, (C) CsA + NG treated group shows increased green fluorescence, (D) NG group showed fewer positive fluorescence. Quantification of $\mathrm{HO}-1$ : The result was quantified per $0.245 \mathrm{~mm}^{2}$ of $\mathrm{HO}-1$ positively stained cells. Hypothesis testing method included one-way analysis of variance (ANOVA) followed by least significant difference (LSD) test. Values are expressed as the mean $\pm \mathrm{SD} .{ }^{a} \mathrm{CsA} v s$. control, ${ }^{\mathrm{b}} \mathrm{CsA}$ vs. CsA + NG, p < 0.05 (magnification 20x; scale bar $100 \mu \mathrm{M}$ ), ns non-significant (NG vs. control)

ment caused a significant reduction of the expression of heme oxygenase (Fig. 4B). The expression was elevated in NG treated animals, whereas Control cells and $\mathrm{NG}$ alone treated groups of animals exhibited moderate expression of HO (Figs. 3A and D). Upon treatment with $\mathrm{NG}$, the expression of $\mathrm{HO}$ was remarkably close to the control animals (Fig. 3C). Indeed, present study suggests that administration of NG increased HO levels, perhaps due to anti-inflammatory properties. This suggests that HO-1 upregulation by NG is responsible, at least in part, for these protective effects.

Figure 4 shows the effect of NG on western blot analysis of HO-1, a stress protein, expression in the 

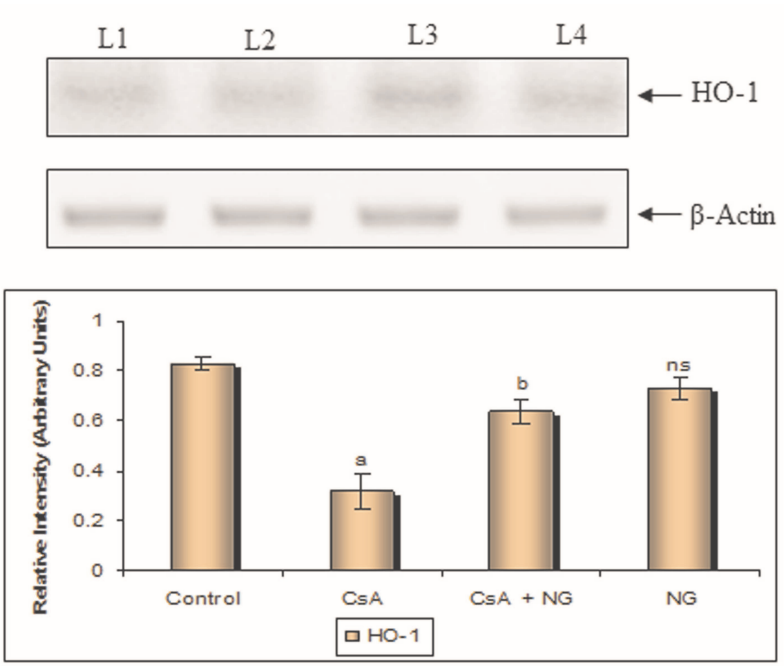

Fig. 4. Effect NG on western blot analysis of $\mathrm{HO}-1$ in control and experimental groups of animals. Lane 1, Lane 2, Lane 3 and Lane 4 correspond to control, CsA, CsA + NG and NG, respectively. Quantitative data expressing the corresponding protein levels were assessed using densitometry and are expressed in relative intensity arbitrary units. Values are expressed as the mean $\pm \mathrm{SD}$. ${ }^{a} \mathrm{CsA}$ vs. control, ${ }^{b} \mathrm{CsA}$ vs. CsA + NG, $\mathrm{p}<0.01$, ns - non-significant (NG vs. control)

renal tissue of control and experimental groups of animals. Administration of CsA (lane 2) significantly decreased the expressions of HO. Supplementation of NG (Group 3; lane 3) significantly elevated the expressions as compared to Group 2. No significant changes in the expressions of HO- 1 were observed in Group 4 animals compared to Control group. $\beta$-Actin was used as a loading control. Quantitative data expressing the corresponding protein levels were assessed using densitometry and are expressed in relative intensity arbitrary units.

\section{Discussion}

Chronic kidney disease (CKD) is a global threat, and health care burden due to CKD has increased worldwide in the past decade. Cyclosporine continues to be the backbone of post transplant immunosuppression. However, side effects associated with CsA treatment are numerous and kidney dysfunction is the main complication of CsA treatment. Many experimental studies suggest that ROS take part in the pathogenesis of several kidney diseases. It has also been implicated in models of acute renal failure induced by gentamycin, glycerol and CsA in animals $[1,18,22]$. In vitro studies have demonstrated that CsA induces lipid per- oxidation in rat kidney and liver microsomes. In vivo studies in rats showed that lipid peroxidation induced by CsA was dose-dependent and paralleled the renal functional alterations, measured as decreased glomerular filtration rate and renal blood flow, and increased renal vascular resistance. Lipid peroxidation index, measured as liberation of conjugate dienes and MDA in renal cortex homogenates, and thiobarbituric acid reactive substances (TBARS) in blood and urine, increased with respect to control animals [59].

Increased plasma and kidney tissue MDA values are observed with CsA administration with excess production of hydrogen peroxide in living cells [21], which then gives rise to increased hydroxyl radical formation. NG has proved to possess lipid lowering, anti-lipoperoxidative and antioxidant properties [45]. Recently, NG has been demonstrated to play an important role in regulating antioxidative capacity by increasing SOD and catalase activities by upregulating the gene expression of SOD, catalase, and glutathione peroxidase [19]. In our present study, the levels of $\mathrm{LPO}$ and $\mathrm{OH}^{\circ}$ were increased in CsA-induced groups compared to control groups. Supplementation of NG significantly reduced the levels of LPO and $\mathrm{OH}^{*}$ due to it's potential antioxidant property.

The antioxidant enzymes SOD, GPx and catalase are the major defense against oxidative damage [17]. Reduction of renal SOD activity in CsA-treated rats was observed in our study, which was similar to the previous studies [29]. Reduced glutathione, together with GPx, is important in maintaining the structure of mitochondrial and cell membranes. Reductions in GPx activity noted in the CsA treated rats in the present study are consistent with results obtained by others [3]. Flavonoids usually contain one or more aromatic hydroxyl groups in their moiety, which is responsible for their antioxidant activity [58]. Naringenin have already been pharmacologically evaluated as a potential antioxidant [50]. Co-supplementation of $\mathrm{NG}$, in the present study, significantly $(\mathrm{p}<0.05)$ increased the tissue level of enzymatic antioxidants compared to CsA-treated rats. This might indicate the usefulness of NG, as an excellent source of antioxidant, in modulating CsA-induced nephrotoxicity.

In this investigation, severe depletion of nonenzymatic antioxidants such as GSH, vitamin C, E, A was observed in kidney tissue homogenate of CsAinduced (Group 2) animals. Vitamin C and E exhibit a protective effect against free radical-induced oxidative damage $[6,13]$. Vitamin $\mathrm{E}$ is the only significant 
lipid-soluble, chain-breaking antioxidant present in human blood cells. Its scavenging effect of oxygen radicals has been clarified in various studies $[44,52]$. Vitamin $C$ imparts its protection by undergoing oxidation to dehydroascorbate. For its reversal to ascorbate, GSH is required. Consequently, when GSH is reduced, there is a fall in the level of vitamin C. Decrease in the levels of vitamins $\mathrm{C}$ and $\mathrm{E}$ during CsA administration leads to increased susceptibility of the tissues to free radical damage. Increased tissue concentration of these antioxidants in NG treated animals may be due to scavenging of free radicals and alleviating oxidative stress.

Thus, histopathological study reveals that CsA administration caused a significant damage to renal ultra structure, showing marked tubular damage being the main reason for nephrotoxicity, which is in accord with previous findings [49]. Additionally, treatment of NG partially recovered CsA-induced degenerative damages in the kidney, which may be due to decreased lipid peroxidation and increased antioxidant enzyme activities. Already NG has been effective in preventing ferric nitrilotriacetate induced oxidative damage in rat kidney [54], which supports the present study.

The importance of HO-1 in dictating the outcome of many diseases are the observations that pharmacological induction or overexpression of HO-1, as well as administration of the different end-products of heme catabolism by HO-1, all have significant beneficial or therapeutic effects in a large number of pathologic conditions. These include, severe sepsis [11, 41, 51], severe malaria [42], ischemia-reperfusion injury $[2,14,31]$, rejection of transplanted organs [8], induction of immunological tolerance [61], autoimmune neuroinflammation [10], restenosis [4, 37], myocardial infarction [27] and, as illustrated more recently, type 2 diabetes and obesity [23].

The mechanism by which HO-1 induces cytoprotection remains unclear. Most of the end products of heme degradation, including biliverdin/bilirubin, ferritin, and carbon monoxide, may potentially modulate oxidative stress. Carbon monoxide may induce vasodilatation that could be protective in situations of organ injury and also has anti-apoptotic and antiinflammatory properties [43].

Heme is a tetrapyrrole with a redox active iron center, and functions as a co-factor for various proteins such as hemoglobin, myoglobin, cytochromes, catalases $[40,30]$. Tissue damage or cell injury can desta- bilize heme proteins and result in free heme which in turn can damage cellular components and disrupt cellular function [33].

It has been reported that the mRNA and protein levels of HO-1, an enzyme responsive to changes in the redox status, vary after treatment with CsA [46]. Alterations in heme oxygenase levels with decreased expression in CsA treated animals indicate that down regulation of HO-1 expression by CsA could be one mechanism underlying CsA-induced toxicity. The CsA-induced decrease in HO- 1 expression is partial and restorable, and attempts to preserve HO levels may attenuate CsA toxicity. Therefore, HO has antioxidant capacity and act as potent anti-inflammatory protein whenever oxidative injury takes place. Indeed, present study suggests that administration of NG increased HO levels, perhaps due to anti-inflammatory properties. This suggests that HO-1 upregulation by $\mathrm{NG}$ is responsible, at least in part, for these protective effects.

Flavonoids, including the aglycones, hesperetin, and naringenin, have been reported to induce heme oxygenase 1 (HO-1) protein expression in macrophages [24] and have proved that HO-1 is involved in the inhibitory mechanism of flavonoids on LPSinduced iNOS and NO production. In that context, similar mechanism would have been implied by NG to upregulate heme oxygenase expression in renal tissues of CsA challenged rats. Thus, the effectiveness of NG administration in preventing renal toxicity is clearly evident by this study and it helps to maintain the HO-1 levels and thus further reduces the oxidative stress by this pathway. This result suggests that HO-1 plays a pivotal role in the maintenance of renal functions by protecting the renal tubular epithelial cells under oxidative stress.

The present study confers that NG co-supplementation significantly decreased the levels of free radicals such as LPO and $\mathrm{OH}^{\circ}$ and enhanced the antioxidant status and restored the normal architecture of kidney in CsA challenged rats. Further expression of HO-1 was maintained during NG treatment which may be the major reason for renoprotection.

\section{References:}

1. Ahmed SS, Strobel HW, Napoli KL, Grevel J: Adenochrome reaction implicates oxygen radicals in metabolism of cyclosporine A and FK-506 in rat and human 
liver microsomes. J Phamacol Exp Ther, 1993, 265, 1047-1054

2. Akamatsu Y, Haga M, Tyagi S, Yamashita K, GraçaSouza AV, Ollinger R, Czismadia E et al.: Heme oxygenase-1-derived carbon monoxide protects hearts from transplant associated ischemia reperfusion injury. FASEB J, 2004, 18, 771-772.

3. Al Khader A, al Sulaiman M, Kishore PN, Morais C, Tariq M: Quinacrine attenuates cyclosporine-induced nephrotoxicity in rats. Transplantation, 1996, 62, 427-435.

4. Balla G, Vercellotti GM, Muller-Eberhard U, Eaton J, Jacob HS: Exposure of endothelial cells to free heme potentiates damage mediated by granulocytes and toxic oxygen species. Lab Invest, 1991, 64, 648-655.

5. Bessey OA, Lowry OH, Brock MJ, Lopez JA: The determination of vitamin A and carotene in small quantities of blood serum. J Biol Chem, 1946, 166, 177-188.

6. Borek C: Dietary antioxidant and human cancer. Integr Cancer Ther, 2004, 3, 333-341.

7. Busauschina A, Schnuelle P, Van der Woude FJ: Cyclosporine nephrotoxicity. Transplant Proc, 2004, 36, 229S-233S.

8. Camara NO, Soares MP: Heme oxygenase-1 (HO-1), a protective gene that prevents chronic graft dysfunction. Free Radic Biol Med, 2005, 38, 426-435.

9. Cederbaum AI, Cohen G: Methods in Enzymology, vol. 105, Ed. Packer L, Academic Press, San Diego, 1984, 516-522.

10. Chora AA, Fontoura P, Cunha A, Pais TF, Cardoso S, Ho PP, Lee LY et al.: Heme oxygenase-1 and carbon monoxide suppress autoimmune neuroinflammation. J Clin Invest, 2007, 117, 438-447.

11. Chung SW, Liu X, Macias AA, Baron RM, Perrella MA: Heme oxygenase-1-derived carbon monoxide enhances the host defense response to microbial sepsis in mice. J Clin Invest, 2008, 118, 239-247.

12. Desai ID: Vitamin $\mathrm{E}$ analysis methods for animal tissues. Methods Enzymol, 1984, 105, 138-147.

13. Fang YZ, Yang S, Wu G: Free radicals, antioxidants, and nutrition. Nutrition, 2002, 18, 872-879.

14. Fujita T, Toda K, Karimova A, Yan SF, Naka Y, Yet SF, Pinsky DJ: Paradoxical rescue from ischemic lung injury by inhaled carbon monoxide driven by derepression of fibrinolysis. Nat Med, 2001, 7, 598-604.

15. Habig WH, Pabst M.J, Jacoby BW: Glutathione S transferase. The first enzymatic step in mercapturic acid formation. J Biol Chem, 1974, 249, 1730-1737.

16. Haenen, GR, Paquay JB, Korthouwer RE, Bast A: Peroxynitrite scavenging by flavanoids. Biochem Biophys Res Commun, 1997, 236, 5591-593.

17. Hagar HH, El-Etter E, Arafa M: Taurine attenuates hypertension and renal function induced by cyclosporine A in rats. Clin Exp Pharmacol Physiol, 2006, 33, 189-196.

18. Inselmann G, Hannemann J, Baumann K: Cyclosporine A induced lipid peroxidation and influence on glucose6-phosphatase in rat hepatic and renal microsomes. Res Commun Chem Pathol Pharmacol, 1990, 68, 189-203.

19. Jeon SM, Bok SH, Jang MK, Lee MK, Nam KT, Park YB, Rhee SJ, Choi MS: Antioxidative activity of nar- ingin and lovastatin in high cholesterol-fed rabbits. Life Sci, 2001, 69, 2855-2866.

20. Kaul TN, Middlenton E Jr, Ogra PL: Antiviral effects of flavanoids on human viruses. J Med Virol, 1985, 15, 71-79.

21. Khan M, Shobha JC, Mohan IK: Spirulina attenuates cyclosporine-induced nephrotoxicity in rats. J Appl Toxicol, 2006, 26, 444.

22. Kim SY, Kim CH, Yoo HJ, Kim YK: Effects of radical scavengers and antioxidant on ischemic acute renal failure in rabbits. Renal Fail, 1999, 21, 1-11.

23. Li M, Kim DH, Tsenovoy PL, Peterson SJ, Rezzani R, Rodella LF, Aronow WS et al.: Treatment of obese diabetic mice with a heme oxygenase inducer reduces visceral and subcutaneous adiposity, increases adiponectin levels, and improves insulin sensitivity and glucose tolerance. Diabetes, 2008, 57, 1526-1535.

24. Lin HY, Shan SC, Chen YC: Anti-inflammatory effect of heme oxygenase 1: Glycosylation and nitric oxide inhibition in macrophages. J Cell Physiol, 2005, 202, 579-590.

25. Lowry OH, Rosebrough NJ, Farr AL, Randall RJ: Protein measurement with the Folin phenol reagent. J Biol Chem, 1951, 193, 265-275.

26. Maridonneau-Parini I, Braquet P, Garay RP: Heterogeneous effect of flavanoids on $\mathrm{K}^{+}$loss and lipid peroxidation induced by oxygen free radicals in human red cells. Pharmacol Res Commun, 1986, 18, 61-72.

27. Melo LG, Agrawal R, Zhang L, Rezvani M, Mangi AA, Ehsan A, Griese DP et al.: Gene therapy strategy for long-term myocardial protection using adeno-associated virus-mediated delivery of heme oxygenase gene. Circulation, 2002, 105, 602-607.

28. Misra HP, Fridovich I: The role of superoxide anion in the auto oxidation of epinephrine and a simple assay of superoxide dismutase. J Biol Chem, 1972, 247, 3170-3175.

29. Mohamadin AM, El-Beshbishy HA, El-Mahdy MA: Green tea extract attenuates cyclosporine A-induced oxidative stress in rats. Pharmacol Res, 2005, 51, 51-57.

30. Muller-Eberhard U, Fraig M: Bioactivity of heme and its containments. Am J Hematol, 1993, 42, 59-62.

31. Nakao A, Otterbein LE, Overhaus M, Sarady JK, Tsung A, Kimizuka K, Nalesnik MA et al.: Biliverdin protects the functional integrity of a transplanted syngeneic small bowel. Gastroenterology, 2004, 127, 595-606.

32. Nath KA: Heme oxygenase-1: a provenance for cytoprotective pathways in the kidney and tissues. Kidney Int, 2006, 70, 432-443.

33. Nath KA, Balla J, Croatt AJ, Vercellotti GM: Heme protein-mediated renal injury: a protective role for 21aminosteroids in vitro and in vivo. Kidney Int, 1995, 47, 592-602.

34. Nath KA, Norby SM: Reactive oxygen species and acute renal failure. Am J Med, 2000, 109, 665-678.

35. Ng TB, Liu F, Wang ZT: Anitoxidative activity of natural products from plants. Life Sci, 2000, 66, 709-723.

36. Ohkawa H, Ohishi N, Yagi K: Assay for lipid peroxides in animal tissues by thiobarbituric acid reaction. Anal Biochem, 1972, 95, 351-358.

37. Ollinger R, Bilban M, Erat A, Froio A, McDaid J, Tyagi $\mathrm{S}$, Csizmadia E et al.: Bilirubin: a natural inhibitor of 
vascular smooth muscle cell proliferation. Circulation, 2005, 112, 1030-1039.

38. Omaye ST, Tumball JD, Sauberlich HE: Selected methods for the determination of ascorbic acid in animal cells, tissues and fluids. Methods Enzymol, 1979, 62, 3-11.

39. Opelz G, Schwarz V, Engelmann A: Long term impact of HLA matching of kidney graft survival in cyclosporine treated recipients. Transplantation Proc, 1991, 23, 373.

40. Otterbein LE, Zuckerbraun BS, Haga M, Liu F, Song R, Usheva A, Stachulak C et al.: Carbon monoxide suppresses arteriosclerotic lesions associated with chronic graft rejection and with balloon injury. Nat Med, 2003, 9, 183-190.

41. Overhaus M, Moore BA, Barbato JE, Behrendt FF, Doering JG, Bauer AJ: Biliverdin protects against polymicrobial sepsis by modulating inflammatory mediators. Am J Physiol Gastrointest Liver Physiol, 2006, 290, G695-G703.

42. Pamplona A, Ferreira A, Balla J, Jeney V, Balla G, Epiphanio S, Chora A et al.: Heme oxygenase-1 and carbon monoxide suppress the pathogenesis of experimental cerebral malaria. Nat Med, 2007, 13, 703-710.

43. Pang QF, Ji Y, Bermúdez-Humarán LG, Zhou QM, Hu G, Zeng Y: Protective effects of a heme oxygenase1-secreting Lactococcus lactis on mucosal injury induced by hemorrhagic shock in rats. J Surgical Res, 2009, 153, 39-45.

44. Parra Cid T, Conejo García JR, Carballo Alvarez F, de Arriba G: Antioxidant nutrients protect against cyclosporine A nephrotoxicity. Toxicology, 2003, 189, 99-111.

45. Rajadurai M, Stanely Mainzen Prince P: Preventive effect of naringin on lipids, lipoproteins and lipid metabolic enzymes in isoproterenol-induced myocardial infarction in Wistar rats. J Biochem Mol Toxicol, 2006, 20, 191-197.

46. Rezzani R, Rodella L, Bianchi R, Goodman AI, Lianos EA: Protective effects of heme-oxygenase expression in cyclosporine A-induced injury. Curr Neurovasc Res, 2005, 2, 157-161.

47. Ribeiro IA, Rocha J, Sepodes B, Mota-Filipe H, Ribeiro $\mathrm{MH}$ : Effect of naringin enzymatic hydrolysis towards naringenin on the anti-inflammatory activity of both compounds. J Mol Catal B Enzym, 2008, 52-53, 13-18.

48. Rotruck JT, Pope AL, Gasther HE, Swanson AB, Hafeman DG, Hoekstra WG: Selenium: biochemical role as a component of glutathione peroxidase. Science, 1973, 179, 588-590.
49. Sabry A, El-Husseini A, Sheashaa H, Abdel-Shafy E, El-Dahshan K, Abdel-Rahim M, Abdel-Kaleek E, Abo-Zena H: Colchicine vs. omega-3 fatty acids for prevention of chronic cyclosporine nephrotoxicity in Sprague Dawley rats: An experimental animal model. Arch Med Res, 2006, 37, 933-940.

50. Santos KF, Oliveria TT, Nagem TJ, Pinto AS, Oliveria MG: Hypolipidemic effects of naringenin, rutin, nicotinic acid and their association. Pharmacol Res, 1999, 40, 493-496.

51. Sarady-Andrews JK, Liu F, Gallo D, Nakao A, Overhaus M, Ollinger R, Choi AM, Otterbein LE: Biliverdin administration protects against endotoxin-induced acute lung injury in rats. Am J Physiol Lung Cell Mol Physiol, 2005, 289, L1131-L1137.

52. Schneider C: Chemistry and biology of vitamin E. Mol Nutr Food Chem, 2005, 49, 7-30.

53. Seo HJ, Jeong KS, Lee MK, Park YB, Jung UJ, Kim HJ: Choi MS: Role of naringin supplement in regulation of lipid and ethanol metabolism in rats. Life Sci, 2003, 73, 933-946.

54. Singh D, Chander V, Chopra K: Protective effect of naringin, a bioflavonoid on ferric nitrilotriacetate-induced oxidative renal damage in rat kidney. Toxicology, 2004, 201, 1-8.

55. Sinha AK: Colorimetric assay of catalase. Anal Biochem, 1972, 47, 389-394.

56. Staal GE, Visser J, Veeger C: Purification and properties of glutathione reductase of human erythrocytes. Biochim Biophys Acta, 1969, 185, 39-48.

57. Ueng YF, Chang YL, Oda Y, Park SS, Liao JF, Lin MF, Chen CF: In vitro and in vivo effects in mouse of naringin on cytochrome $\mathrm{P}_{450}$ dependent monoxygenase in mouse liver. Life Sci, 1999, 73, 933-946.

58. Van Acker FAA, Schouten O, Haenen GR, Van der Vijgh VJF, Bast A: Flavonoids can replace $\alpha$-tocopherol as an antioxidant. FEBS Lett, 2000, 473, 145-148.

59. Wang C, Salahudeen AK: Lipid peroxidation accompanies cyclosporine nephrotoxicity: effects of vitamin E. Kidney Int, 1995, 47, 927-934.

60 . Wongmekiat $\mathrm{O}$, Thamprasert $\mathrm{K}$ : Investigating the protective effects of aged garlic extract on cyclosporineinduced nephrotoxicity in rats. Clin Pharmacol, 2005, 19, 555-562.

61. Yamashita K, McDaid J, Ollinger R, Tsui TY, Berberat PO, Usheva A, Csizmadia E et al.: Biliverdin, a natural product of heme catabolism, induces tolerance to cardiac allografts. FASEB J, 2004, 18, 765-767.

Received: April 5, 2012; in the revised form: May 3, 2013; accepted: May 22, 2013 